Bond University

Research Repository

\title{
Barriers to the transition towards off-site construction in China: An Interpretive structural modeling approach
}

Gan, Xiaolong; Chang, Ruidong; Zuo, Jian; Wen, Tao; Zillante, George

Published in:

Journal of Cleaner Production

DOI:

10.1016/j.jclepro.2018.06.184

Licence:

CC BY-NC-ND

Link to output in Bond University research repository.

Recommended citation(APA):

Gan, X., Chang, R., Zuo, J., Wen, T., \& Zillante, G. (2018). Barriers to the transition towards off-site construction in China: An Interpretive structural modeling approach. Journal of Cleaner Production, 197(1), 8-18. https://doi.org/10.1016/j.jclepro.2018.06.184

\section{General rights}

Copyright and moral rights for the publications made accessible in the public portal are retained by the authors and/or other copyright owners and it is a condition of accessing publications that users recognise and abide by the legal requirements associated with these rights.

For more information, or if you believe that this document breaches copyright, please contact the Bond University research repository coordinator 


\title{
Barriers to the transition towards Off-site construction in China: An Interpretive Structural Modeling approach
}

\author{
Xiaolong Gan ${ }^{\mathrm{a}}$, Ruidong Chang ${ }^{\mathrm{b}}$, Jian Zuo ${ }^{\mathrm{c} *}$, Tao Wen ${ }^{\mathrm{a}}$, George Zillante ${ }^{\mathrm{c}}$
}

${ }^{a}$ College of Economics and Management, Southwest University, Chongqing, China,

${ }^{b}$ Centre for Comparative Construction Research, Faculty of Society and Design, Bond University, Gold Coast, Australia

${ }^{\mathrm{c}}$ School of Architecture and Built Environment, University of Adelaide, SA, 5000, Australia

Abstract: Off-site construction (OSC) has been recognized as an approach to transform the construction sector from a labor-intensive to a modernized and green industry. Despite a number of advantages, the development of OSC still remains its infancy in China due to various interactive barriers. Some studies have been conducted to explore the barriers to the OSC adoption. However, very few studies attempted to investigate the complex interrelationships among these barriers. In order to fill this gap, this study adopts Interpretive Structural Model (ISM) technique to explore the interrelationships amongst barriers to the OSC adoption in China. Firstly, critical barriers were identified through literature review and semi-structured interviews with various stakeholders. Then, the overall structure amongst barriers was revealed through ISM technique. By using the Matrice d'Impacts Croise's Multiplication Appliquée a Classement (MICMAC) technique, the barriers were classified into four groups according to their driving-power and dependence power. The results indicate that specific attentions should be given to inadequate policy and regulations, lacking knowledge and expertise, dominated traditional project process as well as low standardization. The research findings provide valuable information for policy-makers on the overall structure amongst barriers. These results shed lights on effectively developing measures to facilitate the OSC adoption in the construction sector.

Key words: Off-site construction; prefabrication; Critical barriers; China; Interpretive Structural Model

\section{Introduction}

It is well acknowledged that China has one of the largest construction industries over the world (Chang et al., 2016). Along with significant economic contribution, the Chinese construction industry is facing challenge in pursuing the goal of sustainable development. For instance, the construction industry accounted for 20\% of the total energy consumption in China in 2015 (Hong et al., 2017). This proportion might be even higher due to the largest urbanization is experienced

\footnotetext{
*Corresponding author, Email: jian.zuo@adelaide.edu.au; sageorgezuo@yahoo.com.au (J.Zuo)
} 
in China which is expected to a historic of $60 \%$ by 2020 (Gan et al., 2017). It is estimated that around 30 billion $\mathrm{m}^{2}$ of building area will be newly constructed by 2020 according to the National New-type Urbanization Plan (2014-2020) (Gan et al., 2015; SC, 2014). Meanwhile, the labor shortage of on-site construction workers have emerged in major cities of China due to intensive workloads, long working hours and poor living conditions (Wang et al., 2016). There are a number of issues associated with traditional on-site construction method such as low productivity, high waste, heavy environmental burden and poor safety (Teng et al., 2017).

Under off-site construction (OSC), a certain amount of building components are manufactured in a controlled environment, transported to the construction site and assembled into buildings (Hong et al., 2018; Mao et al., 2015). Originated from the manufactured industry, OSC is a radical innovation to replace conventional in-situ construction method (Kamali \& Hewage, 2017; Steinhardt et al., 2013). Currently, the adoption of OSC has made considerable progress in countries and regions such as Japan, Denmark, Netherlands, Sweden, Germany, Hong Kong, Singapore and so on (Jaillon et al., 2010; Mao et al., 2016; Zhai et al., 2014). Lessons derived from these countries and regions highlight the inherent benefits of the OSC, including reducing construction waste, improving quality control, reducing noise and dust, improving health and safety, saving times and costs, lowing labor demand, reducing resource depletion, and a consequence increasing in predictability, productivity, whole-life performance, and profitability (Chiang et al., 2006; Hong et al., 2018; Jaillon \& Poon, 2008; Kamali \& Hewage, 2016; Li et al., 2016; Li et al., 2014; Li et al., 2014; Nadim \& Goulding, 2010; Pan et al., 2012). This indicates that the OSC adoption can be regarded as a good alternative to meet housing demand timely as well as to facilitate the shifting the dependence of construction industry on labor towards a "knowledge -based" industry (Nadim et al., 2011).

The Chinese government has recognized these benefits and regarded the adoption of OSC as an effective tool to facilitate the industrialization of construction industry. OSC is expected to account for $30 \%$ of total construction within the next decade (SC, 2016). It is mandatory to adopt OSC for affordable housing development in many jurisdictions, such as Chongqing, Beijing, and Shenzhen. The total floor area of OSC housing is expected to exceed 40million $\mathrm{m}^{2}$ by 2017 . Meanwhile, in the context of urbanization, the massive housing demand within limited time framework creates best opportunity for its extensive adoption.

The construction industry is well-known for its low level of innovation (Xue et al., 2017). The promotion of adopting OSC is indeed a formidable task for the construction industry as its "lock-in" to the conventional in-site construction method (Zhang et al., 2012). As a sequence, the 
projected market share of OSC in China remains below $2 \%$ of its entire construction sector, far below the national target (Mao et al., 2016). This has motivated studies to explore individual barriers to the OSC adoption in China (Luo et al., 2015; Mao et al., 2015; Zhang et al., 2014). However, the interrelated relationships among barriers have been largely overlooked. Liu et al. (2015) argued that the OSC adoption as innovation is featured with complex, dynamic and non-linear. As extraordinary variety of materials required for the products, the construction is a complex product system (Xue, Zhang, Yang, \& Dai, 2014). The distinguished characteristic of complex product system is that many interconnected elements are organized in a hierarchical way, with nonlinear and continuously emerging properties (Miller et al., 1995). The OSC adoption will introduce changes into this complex system which creates a ripple effect of secondary and tertiary impacts (Slaughter, 2000). Therefore, it is imperative to understand the interrelationships among these barriers so that effective strategies could be developed accordingly. This has been underscored by previous studies that suggested the interactive relationships among barriers to the adoption of construction innovations (Prasad et al. 2015; Luthra et al. 2014; Dalvi-Esfahani et al. 2017). An examination of these interactive relationships provides a comprehensive picture regarding the overall structure of barriers (Wang et al., 2008).

Therefore, this study aims to fill this gap by developing a comprehensive model depicting the barriers and their interactive relationships via the Interactive Structural Modeling (ISM) and Matrice d'impacts croises-multipication appliqué a classement (MICMAC) technique. Specific objectives of this research are: 1) identifying the critical barriers to the OSC adoption; 2) determining the interactive relationships amongst these barriers; 3) prioritizing these barriers. In light of the significant role and urgent need of OSC in the rapid urbanization in China, the research findings help decision makers to visualize the barriers through revealing the overall structure while the model facilitates the identification of high-priority barriers. Corresponding strategies can be developed consequently. This sheds lights on how to facilitate the OSC adoption in developing countries.

\section{Research methods}




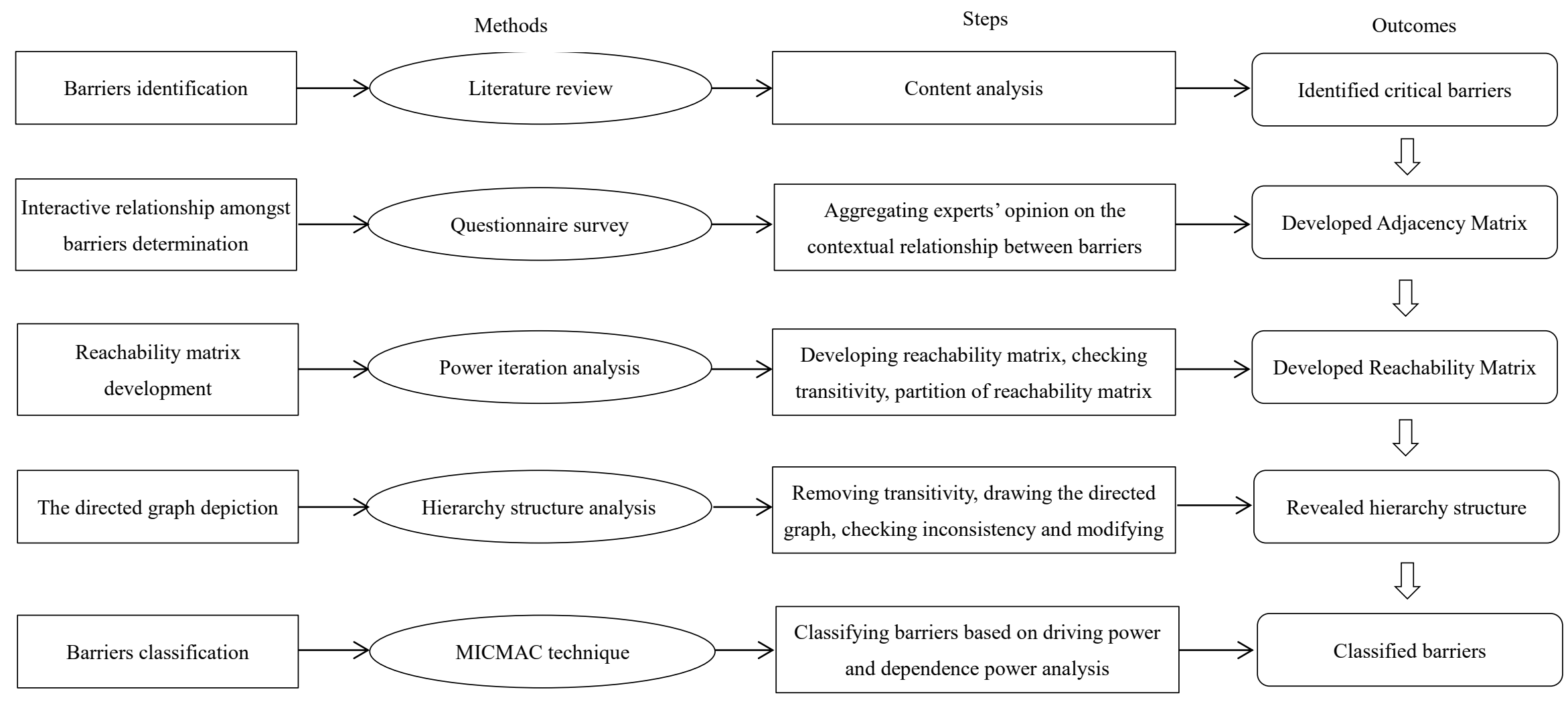

Fig.1 Research process 
To achieve these research objectives, a hybrid research method (Fig.1) was adopted in this study. Firstly, a comprehensive literature review was conducted to identify the barriers to the OSC adoption. This is followed by a questionnaire survey to elicit the perceptions of experts regarding the contextual relationships amongst these barriers. By using Interpretive Structural Model (ISM) technique, the Adjacency Matrix and the Reachability Matrix can be constructed and the hierarchy structure can be depicted after checking transitivity by power iteration analysis. Finally, these barriers were classified according to driving power and dependence power by using the Matrice d' Impacts Croise's Multiplication Appliquée a Classement (MICMAC) technique.

\subsection{ISM}

Interpretive Structural Model (ISM) was first proposed by Warfield in 1974. It is an interpretive modeling technique based on the judgment of working participants in a group to decide whether and how the factors of complex situation are related together (Dalvi-Esfahani et al., 2017; Prasad et al., 2015). ISM provides an effective method to recognize relationships among various items of a complex system (Abuzeinab et al., 2017; Luthra et al., 2014). Meanwhile, ISM has been adopted to highlight the courses of actions to solve the target problem (Dalvi-Esfahani et al., 2017). Currently, ISM has been adopted in the field of construction innovation, e.g. investigating barriers to sustainable business models in UK (Abuzeinab et al., 2017); exploring the interactions among barriers of adoption of smart grid technologies (Luthra et al., 2014); probing the interactions of barriers to implementing OHSAS 18001 in India (Prasad et al., 2015). With a reference of these studies, the basic steps to develop the ISM are as follows (Abuzeinab et al., 2017; Luthra et al., 2014; Prasad et al., 2015):

Step 1: Variables related to the problems or issues under consideration are identified.

Step 2: Identifying the contextual relationship among variables identified in Step 1. The Adjacency Matrix (AM) suggests the contextual relationship among variables that collected opinions from experts. The contextual relationships presenting the pair wise relationships between variables in $\mathrm{AM}$ can be described by using the letters of $\mathrm{V}, \mathrm{X}, \mathrm{A}, \mathrm{O} . V$ means that variable $i$ led to variable $j ; A$ means variable $j$ led to variable i; $X$ means variables $i$ and $j$ led to each other; $O$ means variables $i$ and $j$ were unrelated.

Step 3: Developing a Reachability Matrix (RM). The Adjacency Matrix (AM) demonstrates the direct relationships among barriers, while the Reachability Matrix suggests not only the direct relationships among barriers but also the indirect relationships. Based on the AM, two steps were implemented to develop the RM. Firstly, the initial RM $\left(\mathrm{R}_{\mathrm{i}}\right)$ was developed by using the following rules that the binary values 1 and 0 are adopted to replace V, A, X, O in AM (Shen et al., 2016): 
- If the cell $(i, j)$ entry in the AM was $\mathrm{V}$, the cell $(i, j)$ entry in the Reachability Matrix became 1 and the cell $(j, i)$ entry became 0 .

- If the cell $(i, j)$ entry in the AM was A, the cell $(i, j)$ entry in the Reachability Matrix become 0 and the cell $(j, i)$ became 1 .

- If the cell $(i, j)$ in the AM was X, the cell $(i, j)$ entry in the Reachability Matrix became 1 and the cell $(j, i)$ became 1 .

- If the cell $(i, j)$ entry in the AM was $\mathrm{O}$, the cell $(i, j)$ entry in the Reachability Matrix became 0 and the cell $(j, i)$ also became 0 .

As the initial RM based on AM only demonstrates the direct relationships among variables without telling the indirect relationships, it is necessary to conduct the power iteration analysis. This aims to check transitivity rules, e.g., if $\mathrm{A} \rightarrow \mathrm{B}$ and $\mathrm{B} \rightarrow \mathrm{C}$, then $\mathrm{A} \rightarrow \mathrm{C}$, to reveal the indirect relationships amongst variables. By adding the transitivity to the initial Reachability Matrix through Boolean operation which involved self-multiplication of matrix until it reached a stable state, the final Reachability Matrix can be generated (Wu et al., 2015). According to Shen et al. (2016), the finial RM can be generated using the following equation:

$$
R_{f}=R_{i}^{k}=R_{i}^{k+1}, K>1
$$

Where $R_{f}$ is final Reachability Matrix, and $R_{i}$ is initial Reachability Matrix.

Step 4: Partitioning is carried out to identify various levels of the model. To establish the hierarchy structure, variables' level partitions were identified which is based on reachability set, antecedent set and intersection set. The reachability set of a variable consists of the variables itself and other variables that it may reach, and the antecedent set of a variable consists of the variables itself and other variables that may reach to it, and the interaction set of a variable consists of the common variables in its both reachability and antecedent set (Luthra et al., 2014). The reachability set and antecedent set for each variable was derived from the RM, and then, the intersection set was generated. To determine the level of each variable, the reachability set should be compared with the intersection set (Shen et al., 2016). Variables with the reachability set and intersection set were identical should be considered as pertaining to level 1 . Next, the variables identified in level 1 will be discarded for the next iteration to identify further levels. New reachability set and intersection set for the remaining variables were examined. Variables with the reachability set and intersection set were identical should be considered as pertaining to level 2. The interactions were repeated until all the variables are classified in levels. Then the hierarchy structure is revealed.

Step 5: Drawing the directed graph, and then checking conceptual inconsistency, followed by necessary modifications, if required. 


\subsection{MICMAC techniques}

Matrice d'Impacts Croises Multipication Appliqué a classement (MICMAC) technique is used to investigate how impacts are distributed "through reaction paths and loops for developing hierarchies for members of an element set" (Wang et al., 2008). Generally, it is conducted by examining the driving power and dependence power of each factor. The driving power of a factor suggests the total number of other factors been it affects, while the dependence power refers to the total number of other factors it is affected by (Shen et al., 2016). The driving power and dependence power can be calculated by adding together all the entry values of the row and the column respectively corresponding to the concerned factor in the RM. As a result, each factor can be grouped into four classifications: autonomous factors (weak driving power and weak dependence power), dependent factors (weak driving power and strong dependence power), linkage factors (strong driving power and strong dependence power), and driver or independent factors (strong driving power and weak dependence power) (Luthra et al., 2014).

\subsection{Questionnaire survey}

The questionnaire survey was conducted in the city of Chongqing, a western city in China where is experiencing rapid urbanization. The urbanization rate is expected to reach $70 \%$ in 2020 , where nearly 242 thousand million people live in urban area. The massive ongoing construction activities in the context of urbanization provide a best opportunity to promote the OSC adoption. Based on the "Opinions on accelerating the modernization of the construction industry" issued by the Chongqing municipal government in 2015, all the public housing should adopt OSC from 2017 and the OSC is expected to account for $20 \%$ of the new construction in 2020 . There are more practices to promote the OSC adoption in Chongqing than any other western cities, such as establishing manufacturing base of OSC, constructing demonstrating project, etc.

A snowball sampling technique was employed to recruit experts with rich knowledge and expertise on adopting OSC (Shi et al., 2015). A total of 20 experts were contacted through telephone and e-mails, and 8 experts finally agreed to participate in this research. The total participation rate is $40 \%$. Similar sample size was found in previous studies, e.g., Shen et al. (2016), Wang et al. (2008), Luthra et al. (2014). No previous reference suggested the required minimum number of experts for ISM (Liu et al., 2015). According to Liu et al. (2016), this is common and acceptable in construction research and meaningful results can be obtained when well-developed selection criteria are used for sampling. The profiles of participated experts are shown in table 1. All eight experts hold senior management positions in their respective institutions, and have rich experiences on the OSC. 
Table 1. Profile of experts participated in semi-structured interviews

\begin{tabular}{cccc}
\hline Expert & Working organization & Role in the organization & Years of experience \\
\hline A & University & Professor & 5 \\
B & University & Professor & 8 \\
C & University & Professor & 10 \\
D & Construction authority & Director & 9 \\
E & Manufacturer & Executive & 14 \\
F & Developer & General Manager & 7 \\
G & Designer & Professional Engineer & 13 \\
H & Contractor & Department Manager & 15 \\
\hline
\end{tabular}

These 8 experts were asked to judge whether those barriers identified by literature review are reprehensive in the context of China. Firstly, those barriers identified in section 3 were distributed to experts by email with the requirement to confirm and agree on the interpretation of each of these barriers. In addition, they were invited to list other barriers. Secondly, all 8 experts undertook the pair-wise comparison of the barriers by answering the questions "do you think factor $i$ directly affect the factor $j$ ". The contextual interrelationships among barriers were determined on the agreement among all respondents. However, different experts may judge the pair-wise comparison of two barriers differently. As suggested by Shen et al. (2016), the principle of "the minority gives way to the majority" was adopted to address this issue. In this research, the contextual relationship among barriers was determined if five or more expert agree.

\section{Literature review of barriers to OSC adoption}

To identify barriers to the adoption of OSC, a systematic method was adopted in this study to search and review related literature. Web of Science database was selected. Keywords of "barriers", "offsite construction", or other terms associated with OSC, such as "prefabricated construction", "precast concrete building", "modern methods of construction", "industrialized building", "offsite prefabrication" and so on were used to search the database. These papers were reviewed where a set of barriers were identified.

\section{Higher cost (B1)}

There are mixed results about cost associated with OSC adoption. It has been reported in developed countries that the benefit of cost saving is driver of OSC adoption (Hong et al., 2018; Polat, 2008). It is worth noting that all these countries have extensively adopted OSC or portend a wider uptake in the near future (Mao et al., 2016). As for China, the OSC adoption lagged behind developed countries arguably due to higher cost (Zhang et al., 2014). Besides, the required skilled 
labors might induce higher cost especially in developing countries with lower wages for labors (Chiang et al., 2006; Polat, 2008). Related education and training for unqualified labor also incur cost (Zhai et al., 2014).

\section{Ineffective logistics (B2)}

Logistics related issues imped the OSC adoption, such as limited storage space and transportation constraints (Kamali \& Hewage, 2016; Tam et al., 2007). The constraints of transportation highlighted the carrying capacity of bridge and pavements, clearances in tunnels, and so on (Jaillon et al., 2008). Chiang et al. (2006) suggested most manufactures set their fabrication yards in remote area for cheaper labor and land cost, resulting in longer transportation route. This might incur additional cost but also severe delays in delivering prefabricated components to construction site (Polat, 2010).

\section{Poor manufacturing capacity (B3)}

OSC practices closely associated with the design and manufacturing capacity of manufactures (Mao et al., 2015). Zhang et al. (2014) suggested there is lack of building mould manufacturer in China which satisfy the customized demands. Housing developers have to produce the building blocks as well as to buy it, which stretches the production chain and increases the overall cost. On the other hand, unlike developed countries (e.g. U.S.), most manufacturers in developing countries are small or medium sized without adequate financial resources for quality control procedures and standards (Polat, 2010). This might lead to poor product quality.

\section{Quality problems (B4)}

The quality issue is a paradox when adopting OSC. The high quality is considered as one advantage of adopting OSC, while negative perception from failure or low-quality products has been regarded as prominent factors hindering its wider adoption (Kamali \& Hewage, 2016). Lovell et al. (2010) argued the unproven durability inhibited the extensively adoption of OSC. This is mainly attributed to the poor performance of precast concrete structures in earthquake events (Luo et al., 2015; Polat, 2008). Other quality problems include: cracks and water leakages, poor sound insulation, which has affected its market demand (Zhang et al., 2014). Meanwhile, lacking technical supports (e.g. R\&D, testing lab, and related professionals) lead to poor quality performance (Zhang et al., 2012).

\section{Poor aesthetic performance (B5)}

There are mixed results on the aesthetic performance of OSC adoption as reported in previous studies. OSC allows more flexible designs to achieve more complex patterns (Polat, 2008). 
However, Arditi et al. (2000) argued the monotony is a result of the excessive tendency towards repetitiveness due to higher cost of producing various precast components. Thus, the variations in architectural design are indeed less frequent when adopting OSC (Jaillon et al., 2010). The limited variety of precast concrete components might negatively affect the architectural creativity (Polat, 2010). It probably posed a great challenge for adopting OSC in China, as the design versatility and aesthetic would be actually suffered (Zhai et al., 2014).

\section{Dominated traditional project process (B6)}

The traditional project process is not suitable for adopting OSC (Nadim et al., 2010). Kamali et al. (2016) suggested the OSC adoption requires more time in pre-project planning in order to deal with issues of architectural design, labor and prefabricated components, transportation, technological solutions. However, majority of Chinese residential developers are reluctant to invest on the preparatory phase as excessive time might induce higher capital cost (Zhai et al., 2014). Meanwhile, unable to finalize the design early on has been regarded as significant barrier for adopting prefabrication construction (Pan et al., 2008).

\section{Low standardization (B7)}

The low standardization significantly affects the OSC adoption. It will cause severe compatibility problems occurring especially when multiple manufacturers involved in an OSC project (Polat, 2008). For instance, incompatibility has been regarded as a severe issue in implementing integrated prefabricated façade development $(\mathrm{Li}, 2016)$. This is mainly attributed to lacking peremptory industry norms for OSC, which has been considered as the cornerstone of the overall success of adopting OSC (Zhang et al., 2014). Without a national standard, most of construction components are not standardized, and in turn, makes it hard to design prefabricated building (Mao et al., 2015; Zhang et al., 2012).

\section{Complicated management (B8)}

The OSC adoption requires high level of management. The OSC adoption involves multi-parties, and a high level of integration is required (Luo et al., 2015). However, the poor collaboration has been observed as a result of the fragmented nature of construction industry. It is difficult to develop collaborative relationship between stakeholders in a project-based industry, where each party work individually as an independent organizational entity chasing its own interests (Xue et al., 2017). As Pan et al. (2007) highlighted, unfavorable organizational mechanism was one of barriers of adopting OSC. Similarly, competency of subcontractors is crucial for the OSC adoption (Steinhardt et al., 2016). 


\section{Lacking knowledge and expertise (B9)}

Arditi et al. (2000) pointed that the current curriculum did not address OSC comprehensively especially in developing countries. Lacking expertise of contractors may lead to delays such as erecting the prefabricated structure and panels (Polat, 2008). Meanwhile, the OSC adoption, characterized by a high degree of mechanization, necessitates the presence of sufficiently highly qualified construction workers. Lack of qualified labor leads to poor erection practices which affects the structural ultimately (Polat, 2010).

\section{Inappropriate business model (B10)}

The current business model of construction industry is featured with a cycle of "land acquisition, development and outright sale" (Pan et al., 2012). Such business model may not satisfy the growing challenges from new technologies (Liu et al., 2016). House building is often decoupled from contracting, but focusing on land acquisition and gaining profit from that process. This is mainly because land prices have major effect on the final out-turn costs, representing up to $50 \%$ of total cost in some regions.

\section{Limited market demand (B11)}

The limited market demand presents significant challenge for any salesperson and or developer, so the feasibility of adopting OSC will be doubted (Mao et al., 2015). This will lead to client's skepticism and resistance who actually determines the OSC adoption. Meanwhile, due to fluctuations in the market demand for OSC, high upfront payments are required by manufacturers in order to keep their production and distribution system profitably (Steinhardt et al., 2016). This has been regarded as one of barriers to the wide adoption of OSC mainly attributing to failing to achieve economic scale effects (Arditi et al., 2000; Nadim et al., 2010). The uncertainty of market demand will present enormous difficulty in achieving return on high investment, such as longer capital payback period. This might cause difficulty in obtaining finance from institution which is more familiar with traditional construction approach (Luo et al., 2015; Zhai et al., 2014).

\section{Lacking social climate \& acceptance (B12)}

As the external environment, social climate and acceptance play a critical role in promoting the OSC adoption. As a technological innovation in construction industry, the OSC adoption often attracts resistance, which is attributing to the protectionism and conservatism inherent within the industry culture, namely the risk-averse culture (Nadim et al., 2010). The reluctance to innovation of construction industry has been reported (Pan et al., 2008). The public perception is that prefabricated houses are only for low-income social housing (Nadim et al., 2011). 


\section{Inadequate policies and regulations (B13)}

The intensive OSC adoption cannot be achieved without governmental invention (Zhai et al., 2014). The public policies and regulation instruments facilitating the OSC adoption have been highlighted, which is argued as inadequate and immature in China. Lacking governmental regulations and incentives was identified as the foremost obstacle suggesting insufficient support from government for moving forward OSC adoption (Mao et al., 2015). Regulations of construction sector in China place less emphasis on OSC (Luo et al., 2015; Zhai et al., 2014).

\section{Findings and discussion}

\subsection{Barriers to the OSC adoption}

Those barriers identified in section 3 were distributed to experts by email in the first instance with the requirement to confirm and agree on the interpretation of each of these barriers. Positive feedback was received therefore no change was made to the list of barriers. The final list of critical barriers to the OSC adoption is shown in Table 2. These barriers not only focus on the characteristics of OSC (e.g. cost, logistics, quality, aesthetic), but also involve the environment, relating to market, knowledge and expertise, policies and regulations. These barriers are generally in line with previous studies conducted in China (e.g. Mao et al. 2015; Zhai et al. 2014; Zhang et al. 2014).

Table 2. Barriers of the OSC adoption

\begin{tabular}{|c|c|c|}
\hline No & Factors & Key References \\
\hline B1 & Higher initial cost & (Mao et al., 2016; Zhai et al., 2014; Zhang et al., 2014) \\
\hline B2 & Ineffective Logistics & (Chiang et al., 2006; Pan \& Goodier, 2011; Tam et al., 2007) \\
\hline B3 & Poor Manufacturing capability & (Mao et al., 2015; Polat, 2010) \\
\hline B4 & Quality problems & $\begin{array}{l}\text { (Kamali \& Hewage, 2016; Lovell \& Smith, 2010; Zhang et al., } \\
\text { 2014) }\end{array}$ \\
\hline B5 & Poor aesthetic performances & (Luo et al., 2015; Polat, 2008; Zhai et al., 2014) \\
\hline B6 & $\begin{array}{l}\text { Dominated traditional } \\
\text { process }\end{array}$ & $\begin{array}{l}\text { (Jaillon \& Poon, 2010; Kamali \& Hewage, 2016; Nadim \& } \\
\text { Goulding, 2010) }\end{array}$ \\
\hline B7 & Low standardization & (Arditi et al., 2000; S. Li, 2016; Zhang \& Skitmore, 2012) \\
\hline B8 & Complicated management & (Luo et al., 2015; Steinhardt et al., 2016; Xue et al., 2017) \\
\hline B9 & Lacking knowledge and expertise & (Polat, 2008, 2010; Zhang et al., 2014) \\
\hline B10 & Inappropriate business model & (H. Liu et al., 2016; Pan et al., 2008; Pan \& Goodier, 2011) \\
\hline B11 & Limited market demand & $\begin{array}{l}\text { (Arditi et al., 2000; Nadim \& Goulding, 2011; Steinhardt et al., } \\
\text { 2016) }\end{array}$ \\
\hline B12 & Lacking social climate \& acceptance & (Polat, 2010; Steinhardt et al., 2016) \\
\hline B13 & Inadequate policies and regulations & (Jaillon \& Poon, 2010; Mao et al., 2015; Zhai et al., 2014) \\
\hline
\end{tabular}

It is worth noting that the barrier related to regulations and policies was not regarded as critical 
barrier to OSC adoption within the context of USA (Arditi et al., 2000; Polat, 2008); Hong Kong (Tam et al., 2007), United Kingdom (Nadim et al., 2011; Pan et al., 2008), and Sweden (Jonsson et al., 2014). This might suggest that regulations and policies of these countries have been well established, facilitating the OSC adoption. Similarly, the critical role of labor union has been highlighted in previous studies, e.g. Arditi et al. (2000), and Polat (2008), which was not identified in this study. This might be explained by two reasons. First, as Polat (2010) argued, the labor union's negative attitude might prevent the OSC extensive adoption as they tend to protect their workers as the reduction of work onsite. This probably demonstrates that the labor union plays a critical role in the diffusion of technological innovation in western countries. However, the role of labor union in China might be different from other countries due to different political system. Second, as mentioned in the section 1, with the emergency of labor shortage, the Chinese construction industry actually is suitable for promoting the OSC adoption. Attributing to the "dirty, bitter, and tired" working environment, the new generation of young migrant workers is more likely to decline to engage in the construction industry (Wang et al., 2016). With the improvement of working environment as well as higher salary, it seems that the potential unemployment issue will not be concerned as a barrier of the OSC adoption.

\subsection{ISM}

\section{Building Adjacency Matrix}

Following the principle of "the minority gives way to the majority", the contextual relationships among 13 barriers are constructed in an Adjacency Matrix based on the feedback from 8 experts (Table 3). Most direct-effect relationships were found between B13 (Inadequate policies and regulations) and other barriers, B9 (Lacking knowledge and expertise) and other barriers, and B1 (Higher cost) and other barriers. The least direct-effect relationships were between B10 and other barriers, B7 and other barriers.

Table 3. Adjacency Matrix

\begin{tabular}{llllllllllllll}
\hline & B13 & B12 & B11 & B10 & B9 & B8 & B7 & B6 & B5 & B4 & B3 & B2 & B1 \\
\hline B1 & V & O & X & O & V & V & O & V & A & X & V & V & \\
B2 & V & O & O & O & V & O & O & O & A & O & O & & \\
B3 & V & O & A & O & V & O & O & O & A & A & & & \\
B4 & O & A & A & O & V & O & V & V & O & & & & \\
B5 & O & A & A & O & V & O & O & O & & & & & \\
B6 & V & O & O & O & O & A & O & & & & & \\
B7 & V & O & O & O & A & O & & & & & & & \\
B8 & V & O & O & O & V & & & & & & & & \\
\hline
\end{tabular}




\begin{tabular}{lllll}
\hline B9 & V & A & A & O \\
B10 & V & O & O & \\
B11 & V & V & & \\
B12 & V & & & \\
B13 & & & & \\
\hline
\end{tabular}

\section{Developing Reachability Matrix}

By applying the transformation rules described above, the Adjacency Matrix with the binary value 1 and 0 can be obtained. By aid of the computation tool MATLAB to conduct the power iteration analysis, the transitivity rules have been checked. Any entry $1^{*}$ represent the incorporating the transitivity. For instance, B2 (Ineffective logistics) is related to B1 (Higher cost), and B1 is related to B4 (Quality problems), then, B2 (Ineffective logistics) is necessarily related to B4 (Quality problem). By adding transitivity to Adjacency Matrix, the final Reachability Matrix can be obtained (Table 4).

Table 4. The Final Reachability Matrix

\begin{tabular}{|c|c|c|c|c|c|c|c|c|c|c|c|c|c|c|}
\hline & B13 & B12 & B11 & B10 & B9 & B8 & B7 & B6 & B5 & B4 & B3 & B2 & B1 & Dri \\
\hline B1 & 0 & $1^{*}$ & 1 & 0 & 0 & 0 & 0 & 0 & 1 & 1 & 0 & 0 & 1 & 5 \\
\hline B2 & 0 & $1^{*}$ & $1^{*}$ & 0 & 0 & 0 & 0 & 0 & 1 & $1^{*}$ & 0 & 1 & 1 & 6 \\
\hline B3 & 0 & $1^{*}$ & 1 & 0 & 0 & 0 & 0 & 0 & 1 & 1 & 1 & 0 & 1 & 6 \\
\hline B4 & 0 & 1 & 1 & 0 & 0 & 0 & 0 & 0 & $1^{*}$ & 1 & 0 & 0 & 1 & 5 \\
\hline B5 & 0 & 1 & 1 & 0 & 0 & 0 & 0 & 0 & 1 & $1^{*}$ & 0 & 0 & $1^{*}$ & 5 \\
\hline B6 & 0 & $1^{*}$ & $1^{*}$ & 0 & 0 & 1 & 0 & 1 & $1^{*}$ & 1 & 0 & 0 & 1 & 7 \\
\hline B7 & 0 & $1^{*}$ & $1^{*}$ & 0 & 1 & 0 & 1 & 0 & $1^{*}$ & 1 & 0 & 0 & $1^{*}$ & 7 \\
\hline B8 & 0 & $1^{*}$ & $1^{*}$ & 0 & 0 & 1 & 0 & 0 & $1^{*}$ & $1^{*}$ & 0 & 0 & 1 & 6 \\
\hline B9 & 0 & 1 & 1 & 0 & 1 & 1 & 0 & 0 & 1 & 1 & 1 & 1 & 1 & 9 \\
\hline F10 & 0 & 0 & 0 & 1 & 0 & 0 & 0 & 0 & 0 & 0 & 0 & 0 & 0 & 1 \\
\hline B11 & 0 & $1^{*}$ & 1 & 0 & 0 & 0 & 0 & 0 & $1^{*}$ & $1^{*}$ & 0 & 0 & 1 & 5 \\
\hline B12 & 0 & 1 & 1 & 0 & 0 & 0 & 0 & 0 & $1^{*}$ & $1^{*}$ & 0 & 0 & $1^{*}$ & 5 \\
\hline B13 & 1 & 1 & 1 & 1 & 1 & 1 & $1^{*}$ & $1^{*}$ & $1^{*}$ & 1 & 1 & 1 & 1 & 13 \\
\hline Dep & 1 & 12 & 12 & 2 & 3 & 4 & 2 & 2 & 12 & 12 & 3 & 3 & 12 & \\
\hline
\end{tabular}

Noting: Dep=dependence power; Dri= Driving power;

\section{Establishing the hierarchy structure}

Based on the Reachability Matrix, the reachability set and antecedent set of every barrier can be found by conducting the procedures described in section 3.2. As a result, all barriers are classified into different levels (Table 5). It can be observed that level 1 includes 6 barriers, namely B1, B4, B5, B10, B11, B12, and 3 barriers were classified into level 2 such as, B2, B3, and B8. The lower level might suggest these barriers would be at the top of the hierarchy and would not lead to other 
barriers above their own level. In other words, these barriers are likely to be affected by other barriers. Higher level indicates these barriers situated in the bottom of the hierarchy and can exert great influences to the adoption of OSC. It deserved to notice that only one barrier was classified into level 4 and level 5, containing B7, and B13 respectively. Barriers of B6 and B9 were classified to level 3 indicating they not only influence the barriers in higher level but also would be affected by these barriers in lower level.

Table 5. Level partitioning factors

\begin{tabular}{lllll}
\hline Factor & \multicolumn{1}{c}{ Reachability set } & \multicolumn{1}{c}{ Antecedent set } & Intersection set & Level \\
\hline B1 & $1,4,5,11,12$ & $1,2,3,4,5,6,7,8,9,11,12$ & $1,4,5,11,12$ & 1 \\
B2 & $1,2,4,5,11,12$ & $2,9,13$ & 2 & 2 \\
B3 & $1,3,4,5,11,12$ & $3,9,13$ & 3 & 2 \\
B4 & $1,4,5,11,12$ & $1,2,3,4,5,6,7,8,9,11,12$ & $1,4,5,11,12$ & 1 \\
B5 & $1,4,5,11,12$ & $1,2,3,4,5,6,7,8,9,11,12$ & $1,4,5,11,12$ & 1 \\
B6 & $1,4,5,6,8,11,12$ & 6,13 & 6 & 3 \\
B7 & $1,4,5,7,9,11,12$ & 7,13 & 7 & 4 \\
B8 & $1,4,5,8,11,12$ & $6,8,9,13$ & 8 & 2 \\
B9 & $1,2,3,4,5,8,9,11,12$ & $7,9,13$ & 9 & 3 \\
B10 & 10 & 10,13 & 10 & 1 \\
B11 & $1,4,5,11,12$ & $1,2,3,4,5,6,7,8,9,11,12$ & $1,4,5,11,12$ & 1 \\
B12 & $1,4,5,11,12$ & $1,2,3,4,5,6,7,8,9,11,12$ & $1,4,5,11,12$ & 1 \\
B13 & $1,2,3,4,5,6,7,8,9,10,11,12,13$ & 13 & 13 & 5 \\
\hline
\end{tabular}




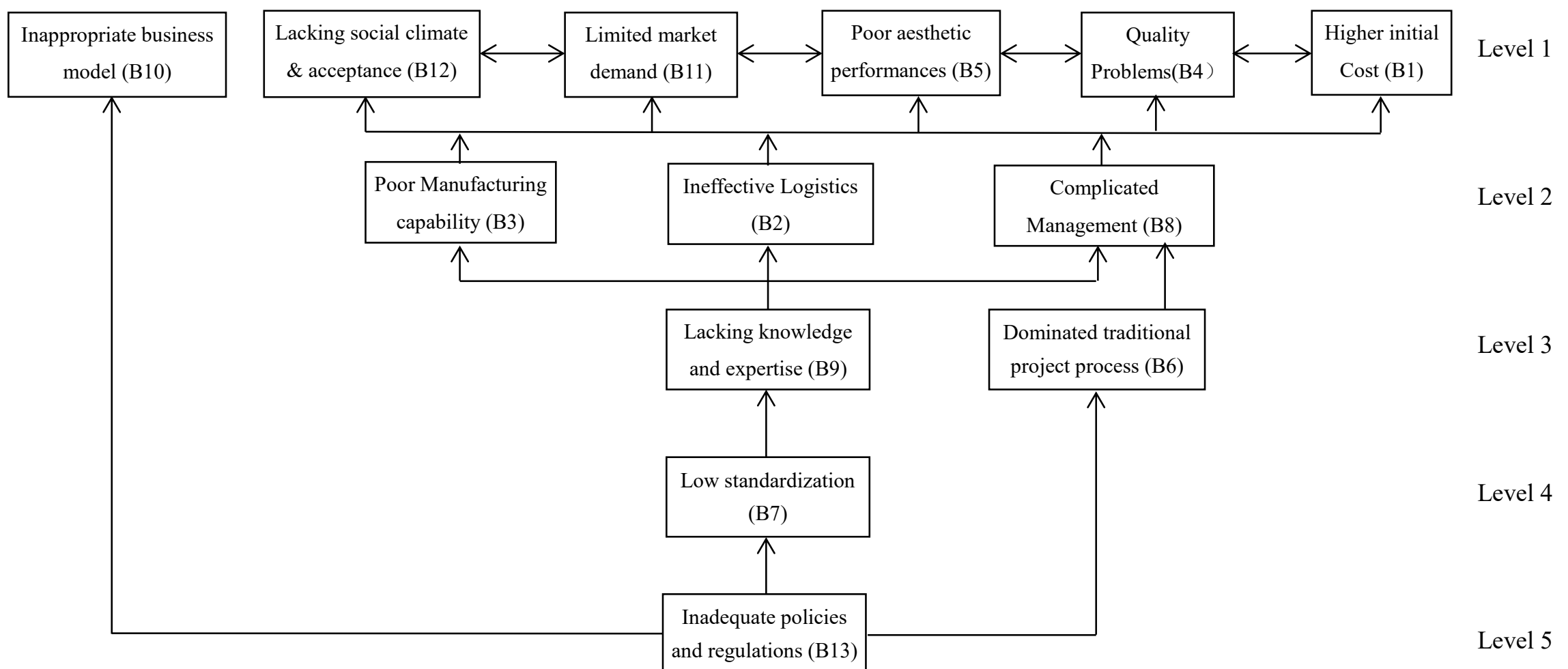

Fig 2. ISM based hierarchical model for barriers to adopt OSC. 
As shown in Fig.2, this study demonstrated the interactive relationships amongst barriers. It should be pointed that this does not provide a step by step roadmap for action but depict the chain of influence of barriers in the system. These research findings help to better understand the effect of these barriers by positioning them in a hierarchy structure. Based on the results of level partitioning, the hierarchical structural model can be developed. As shown in Fig 2, Level 5 B13 (Inadequate policies and policies) is at the bottom of the ISM hierarchy, indicating that it is the most crucial impediment of the OSC adoption in Chinese construction sector. Effectively dealing with this barrier will to a large extent facilitate the OSC adoption in the Chinese construction sector. It should be noted that barrier B7 (Low standardization) situated at the fourth level of the ISM hierarchy, also exhibits great influences on the OSC adoption.

At the same time, 5 barriers occupy the middle portion of the ISM model ranging from B8 (Complicated management), B3 (Poor manufacturing capability), B2 (Ineffective logistics), B6 (Dominated traditional project process), B9 (Lacking knowledge and expertise). Among this, level 3 B6 (Dominated traditional project process) and B9 (Lacking knowledge and expertise) directly affect level 2 B2 (Ineffective logistics), B3 (Poor manufacturing capability) and B8 (Complicated management), and play a role in connecting the level 2 and level 4. Similarly, level 2 B2 (Ineffective logistics), B3 (Poor manufacturing capability) and B8 (Complicated management) play a connecting role between level 1 and level 3 . These barriers paly a connecting role in the hierarchy structure suggests they will affect the barriers in the lower levels and could be affected by the barriers in the higher levels.

Meanwhile, it can be inferred that level 1 includes 6 barriers, such as B1 (Higher cost), B4 (Quality problem), B5 (Poor aesthetic performance), B10 (Inappropriate business mode), B11 (Limited market demand), B12 (Lacking social climate \&acceptance), situating at the top of the ISM model, suggesting their lower influences to the OSC adoption and they are likely to be affected by other barriers. However, this might be contradicted with previous studies, e.g., Nadim and Goulding (2010) and Zhang et al. (2014), which considered higher cost as the most influential barriers of the wider using of OSC. This difference can be explained with the identification of the interactive relationships between these barriers. As the issue of higher cost situating at the bottom of the hierarchical structure is likely to be affected by others barriers, it cannot be regarded as essential factors affecting the OSC adoption. This might demonstrate the effect of high cost inhibiting the OSC adoption can be alleviated by measures and actions targeted to other factors which have direct affect. 


\subsection{MICMAC analysis}

As shown in table 5, the driving power and dependence power for each barrier can be calculated. The two-dimension chat can be generated as shown in Fig. 3. Then, these 13 barriers can be classified into four groups. It should be noted that none of these barriers belong to relay factors. There are four independent barriers with high influence power and low dependence power: B6 (Dominated traditional project process), B7 (Low standardization), B9 (Lacking knowledge and expertise), B13 (Inadequate policies and regulations). There are six depending barriers with low influence power and high dependence power: B1 (Higher cost), B4 (Quality problems), B5 (Poor aesthetic performances), B11 (Limited market demand), B12 (Lacking social climate \& attitudes). Autonomous barriers with low influence and low dependence power contain only 4 barriers: B2 (Ineffective Logistics), B3 (Poor Manufacturing capability), B8 (Complicated management), B10 (Inappropriate business model).

\begin{tabular}{|c|c|c|c|c|c|c|c|c|c|c|c|c|}
\hline 13 & $\mathbf{B}_{13}$ & & & & & & & & & & & \\
\hline \multicolumn{13}{|l|}{12} \\
\hline 11 & \multicolumn{4}{|c|}{ Independent factors } & & & & \multicolumn{3}{|c|}{ Linkage factors } & & \\
\hline \multicolumn{13}{|l|}{10} \\
\hline 9 & & & B9 & & & & & & & & & \\
\hline \multicolumn{13}{|l|}{8} \\
\hline 7 & & $\mathbf{B}_{6,7}$ & & & & & & & & & & \\
\hline 6 & & & $\mathbf{B}_{2,3}$ & B8 & & & & & & & & \\
\hline 5 & & & & & & & & & & & & $B_{1,4,5,11,12}$ \\
\hline \multicolumn{13}{|l|}{4} \\
\hline 3 & \multicolumn{4}{|c|}{ Autonomous factors } & & & \multicolumn{4}{|c|}{ Dependent factors } & & \\
\hline \multicolumn{13}{|l|}{2} \\
\hline \multirow[t]{2}{*}{1} & & $\mathbf{B}_{10}$ & & & & & & & & & & \\
\hline & 1 & 2 & 3 & 4 & 5 & 6 & 7 & 8 & 9 & 10 & 11 & 12 \\
\hline
\end{tabular}

Fig 3. The driving power and dependence power of each barrier to adopt OSC.

The results of MICMAC analysis complement the ISM hierarchy structure by identifying the driving power and dependence power of each barrier. Putting together these results is constructive as it can guide us more effectively develop and implement actions and strategies. It can be observed that B13 (inadequate policies and regulations) lied in the bottom level of the hierarchy structure (Fig.2) and has highest driving power (Fig.3). Therefore, the top priority should be given to address the effect of B13 (inadequate policies and regulations). This result confirms the findings of previous studies (e.g. Mao et al. 2015, Zhang et al. 2014; Zhai et al. 2014), highlighting critical 
role of related regulations and policies in promoting the OSC adoption. As it represented in table 3 and table 4, the B13 (Inadequate policies and regulations) can exert direct or indirect influence to all other barriers. This not only implies that B13 is the most influential barrier to the OSC adoption but also suggests that the effect of other barriers can be alleviated by addressing this barrier. In other words, it is necessary to incorporate the issues of all other barriers into the policies and regulations. Despite this, the policies and regulations issued by Chinese government is still inadequate and ineffective in facilitating the OSC adoption.

Addressing the effect of B9 (Lacking knowledge and expertise) should also be given priority as which situated at the level 3 with the second highest driving power. As shown in the Reachability Matrix (Table 5), B9 (Lacking knowledge and expertise) can exert direct influence on 9 barriers, ranging from $\mathrm{B} 1, \mathrm{~B} 2, \mathrm{~B} 3, \mathrm{~B} 5, \mathrm{~B} 8, \mathrm{~B} 9, \mathrm{~B} 11$ and $\mathrm{B} 12$. This imply addressing the effect of $\mathrm{B} 9$ (Lacking knowledge and expertise) can relieve the effects of these barriers affected by itself. This is in line with previous studies (e.g. Luo et al., 2015; Nadim and Goulding, 2011), regarding the positive effect of training and education on facilitating the OSC adoption. The resistance to OSC can be alleviated by a better understanding of its benefits, and meanwhile, the capabilities of adopting OSC can also be improved with refers to the issues of logistics, manufacturing and the implementing process. Once the know-how of OSC adoption possessed by stakeholders, a new process model integrated process from conception to demolition phases will be anticipated. However, as Polat (2008) pointed, teaching the knowledge of OSC has not been given priority by educational institutions when they designing their academic curricula. Therefore, it is necessary to develop new course of the OSC adoption in civil engineering and architecture programs and specially training in masters programs to teach structural, architectural, and managerial aspect of OSC adoption. Besides, the training programs should also be made for different practitioners specifically. For instance, as Luo et al. (2015) suggested, cost-benefits analysis should be highlighted for client, a course of manufacturing and component assembly will benefit contractors, design features and methods could emphasized for designers.

Similarly, B6 (dominated traditional project process) situating at the level 3 was perceived with the third highest driving power. This indicates that addressing the effect of B6 (dominated traditional project process) should also be given priority. In combination with the hierarchy structure (Fig.2) and the Reachability Matrix (Table 5), it is clearly that B6 (dominated traditional project process) has direct influences on the barriers of B1 (Higher cost), B4 (Quality problem), B8 (Complicated management). This is can be said that the traditional project process is no longer suitable for the OSC adoption causing the poor performances in terms of cost, quality and management. Indeed, as Polat (2008) pointed, severe delay in production and erection schedules, 
substantial cost overruns and constructability problems may be encountered unless good communications and coordination is achieved among all the key parties. While, the traditional project process has been criticized for involved parties working individually with its own target resulting the low level of shared information and communication (Zhai et al., 2014). It is recommended that the conception integration should be applied at all phases and within and between organizations involved in the process of adopting OSC. This can address the conflicts among contractors, manufacturers and designers, leading to severe time delays in production and erection schedule, and substantial cost overruns (Arditi et al., 2000; Polat, 2008). Furthermore, an integrated supply chain with responsive and reliable relationship is strongly recommended by Steinhardt et al. (2016). This helps to form strategic partnering as well as co-makership relationships between contractors, manufacturers, which provide the benefits of fully-customizable end products, shared technical information and so on. Meanwhile, the issue of ineffective logistics might be well addressed by their better coordination and negotiations.

The fourth barriers should be given priority is B7 (Low standardization) situating at the level 4 of the hierarchy structure with the third highest driving power. As it can be seemed from Fig.2, B7 (Low standardization) was included in three influence chains which generally highlighted the low standardization (B7) leading to the lacking knowledge and expertise (B9), and then, the ineffective logistics (B2) and poor manufacturing capability (B3), and resulting quality problem (B4), poor aesthetic performance (B5), lacking social climate \&attitude (B12), and limited market demand (B11). All these factors finally lead to the high cost (B1). This probably suggests the low standardization can be concerned as one of the most influential barriers of the OSC adoption. Thus, it is urgent to establish the national codes and standards for adopting OSC. This is in line with previous studies (e.g. Polat 2010; Polat 2008; Zhang et al. 2014; Zhai et al. 2014), suggesting that the establishment a nationwide standardization is the basis of the further development of OSC adoption. Three technical norms for prefabricated concrete structure building (GB/T51231-2016), prefabricated steel structure building (GB/T51232-2016) and prefabricated timber structure building (GB/T51233-2016) have been issued by Ministry of Housing and Urban-Rural Development in 2017. This provides technical guidelines for the OSC adoption in terms of design, install, construct, and operate. However, as Y. Gan et al. (2017) argued, the production norms and standards for OSC components as well as the quality criteria for component products is still lacking. As a sequence, manufacturers have to set their own quality management method leading to the inconsistency of the quality standards and quality problems. One of the effective ways of standardization is to establish a modulus system (Zhang et al. 2014).

The five dependent barriers (B1, B4, B5, B11, B12) in Fig.3 are affected by diving barriers and 
linkage barriers. As Shen et al. (2016) suggested, dependent barriers can be improved if driving barriers can be well addressed. For instance, the performance of dependent barrier B12 (lacking social climate \& acceptance) is largely determined by lacking knowledge and expertise (B9), which is a driving barrier. This suggests that efforts are required to educate the public on the benefits of the OSC adoption through various avenues, such as newspapers, demonstration projects, seminars and workshops, etc. As a result, the general public's recognition of OSC can be enhanced, and then, their negative perception will be improved gradually. If the driving barrier of lacking knowledge and expertise (B9) provides strong support by issuing effective policies (B13), the performance of poor manufacturing capability (B3), ineffective logistics (B2), and complicated management (B8) will be improved accordingly. Consequently, not only the lacking social climate \& acceptance (B12) but also other dependent barriers (B11, B5, B4, and B1) will be improved. Then, the addressed barrier of limited market demand (B11) will further improve the barrier of lacking social climate \& acceptance (B12).

\section{Conclusions}

Rapid urbanization and the emergence of information technology for construction industry provide best opportunity for adopting OSC. There are a number of benefits associated with OSC adoption such as cost savings, time savings, less waste and improved efficiency. However, The OSC adoption still remains its infancy in China. This research identified 13 critical barriers to the OSC adoption. By conducting ISM analysis, these 13 barriers are structured in a hierarchy, and divided into five distinct levels. Then, by applying the MICMAC analysis, one autonomous factor, six independent factors, and seven dependent factors were identified in Fig 3. It is more effective to address the independent factors as they are most influential to impede the OSC adoption. Similarly, the advantages of OSC can be used to reduce the intensity of barriers.

Previous studies generally only identified critical factors that affect the OSC adoption. In contrast, this study is the unique effort in understanding the interactive relationship among these factors. The ISM based hierarchy model sheds lights on how these factors affect each other. Findings reveal the nature of structural relationships, which substantially contribute towards policy formulation for effectively facilitating the OSC adoption. The factors are positioned in a two-dimensional diagram according to their driving-power and dependence-power. These findings provide valuable insights on the priority of allocating resources to address these factors. Understanding the priority of these factors provides essential information for policies makers to facilitate the OSC adoption. 
There are some policy implications from this study. Firstly, as the OSC adoption results in less works on-site, it is necessary to take the labor unions' attitude into consideration when adopting technological innovations. Due to different political system, the role of labor union in China might not be as crucial as it plays for the OSC adoption in western countries. Secondly, the findings of this research suggest the high cost might not be the most influential factor to the OSC adoption as presented in other studies. According to the ISM based model, the issue of high cost can be alleviated by the enforcement of measurements addressing other factors which have direct effect on this factor. Thirdly, the results of MICMAC analysis suggest that the effectiveness of promoting the OSC adoption largely depends on addressing the following issues: inadequate policies and regulations, lacking knowledge and expertise, dominated traditional project process and the low standardization. Other factors with high influence power also deserve more attentions such as ineffective logistics, poor manufacturing capability, complicated management, and so on.

One limitation of this study is the developed model is derived from experts' opinions and experts were drawn from a single region, i.e. Chongqing. Thus, similar research can be conducted in other cities in China as the level of adopting OSC varies from one city to another. This helps to better understand the different structural relationships among these factors as well as exploring the unique measures to promoting the OSC adoption in different regions. Meanwhile, Future research opportunities exist to quantify these interrelationships via a large scale nationwide questionnaire survey.

\section{Acknowledgements}

This study is supported by the 2018 Faculty Research Grant of Bond University, China Postdoctoral Science Foundation (No.2017M6229950), Fundamental Research Funds for the Central Universities (No.SWU1809124) and (No.SWU1409101), Chongqing Social Science Foundation (No. 2017QNGL51) and Chongqing Postdoctoral Science Foundation (No. XM2017155).

\section{References}

Abuzeinab, A., Arif, M., \& Qadri, M. A. (2017). Barriers to MNEs green business models in the UK construction sector: An ISM analysis. Journal of Cleaner Production. 160, 27-37

Agi, M. A., \& Nishant, R. (2017). Understanding influential factors on implementing green supply chain management practices: An interpretive structural modelling analysis. Journal of environmental management, 188, 351-363.

Arditi, D., Ergin, U., \& Günhan, S. (2000). Factors affecting the use of precast concrete systems. Journal of architectural engineering, 6(3), 79-86.

Chang, R. D., Zuo, J., Soebarto, V., Zhao, Z. Y., Zillante, G., \& Gan, X. L. (2016). Sustainability transition of the Chinese construction industry: Practices and behaviors of the leading construction firms. Journal of Management in Engineering, 32(4), 05016009. 
Chiang, Y. H., Chan, H. W., \& Lok, K. L. (2006). Prefabrication and barriers to entry\&mdash;a case study of public housing and institutional buildings in Hong Kong. Habitat International, 30(3), 482-499.

Dalvi-Esfahani, M., Ramayah, T., \& Nilashi, M. (2017). Modelling upper echelons' behavioural drivers of Green IT/IS adoption using an integrated Interpretive Structural Modelling-Analytic Network Process approach. Telematics and Informatics, 34(2), 583-603.

Gan, X., Zuo, J., Wu, P., Wang, J., Chang, R., \& Wen, T. (2017). How affordable housing becomes more sustainable? A Stakeholder Study. Journal of Cleaner Production. 162, 427-437.

Gan, X., Zuo, J., Ye, K., Skitmore, M., \& Xiong, B. (2015). Why sustainable construction? Why not? An owner's perspective. Habitat International, 47, 61-68.

Gan, Y., Shen, L., Chen, J., Tam, V. W., Tan, Y., \& Illankoon, I. M. (2017). Critical Factors Affecting the Quality of Industrialized Building System Projects in China. Sustainability, 9(2), 216.

Hong, J., Li, C. Z., Shen, Q., Xue, F., Sun, B., \& Zheng, W. (2017). An Overview of the driving forces behind energy demand in China's construction industry: Evidence from 1990 to 2012. Renewable and Sustainable Energy Reviews, 73, 85-94.

Hong, J., Shen, G. Q., Li, Z., Zhang, B., \& Zhang, W. (2018). Barriers to promoting prefabricating construction in china: a cost-benefit a. Journal of Cleaner Production, 172(20), 649-660.

Jaillon, L., \& Poon, C. S. (2008). Sustainable construction aspects of using prefabrication in dense urban environment: a Hong Kong case study. Construction Management and Economics, 26(9), 953-966.

Jaillon, L., \& Poon, C. S. (2010). Design issues of using prefabrication in Hong Kong building construction. Construction Management and Economics, 28(10), 1025-1042.

Ji, Y., Zhu, F., Li, H. X., \& Al-Hussein, M. (2017). Construction Industrialization in China: Current Profile and the Prediction. Applied Sciences, 7(180), 1-13.

Jonsson, H., \& Rudberg, M. (2014). Classification of production systems for industrialized building: a production strategy perspective. Construction Management and Economics, 32(1-2), 53-69.

Kamali, M., \& Hewage, K. (2016). Life cycle performance of modular buildings: A critical review. Renewable \& Sustainable Energy Reviews, 62, 1171-1183.

Kamali, M., \& Hewage, K. (2017). Development of performance criteria for sustainability evaluation of modular versus conventional construction methods. Journal of Cleaner Production, 142, 3592-3606.

Li, C. Z., Hong, J., Xue, F., Shen, G. Q., Xu, X., \& Mok, M. K. (2016). Schedule risks in prefabrication housing production in Hong Kong: a social network analysis. Journal of Cleaner Production, 134, 482-494.

Li, S. (2016). Barriers to Implement Integrated Prefabricated Facade Development in A Traditional Procurement Context in China: A Case Study. Procedia Engineering, 161, 1683-1689.

Li, Z., Shen, G. Q., \& Alshawi, M. (2014). Measuring the impact of prefabrication on construction waste reduction: An empirical study in China. Resources Conservation and Recycling, 91(5), 27-39.

Li, Z., Shen, G. Q., \& Xue, X. (2014). Critical review of the research on the management of prefabricated construction. Habitat International, 43(3), 240-249.

Liu, G., Li, K., Zhao, D., \& Mao, C. (2016). Business Model Innovation and Its Drivers in the Chinese Construction Industry during the Shift to Modular Prefabrication. Journal of Management in Engineering, 33(3), 04016051. 
Liu, H., Skibniewski, M. J., \& Wang, M. (2016). Identification and hierarchical structure of critical success factors for innovation in construction projects: Chinese perspective. Journal of Civil Engineering and Management, 22(3), 401-416.

Lovell, H., \& Smith, S. J. (2010). Agencement in housing markets: The case of the UK construction industry. Geoforum, 41(3), 457-468.

Luo, L. Z., Mao, C., Shen, L. Y., \& Li, Z. D. (2015). Risk factors affecting practitioners' attitudes toward the implementation of an industrialized building system: A case study from China. Engineering, Construction and Architectural Management, 22(6), 622-643.

Luthra, S., Kumar, S., Kharb, R., Ansari, M. F., \& Shimmi, S. L. (2014). Adoption of smart grid technologies: An analysis of interactions among barriers. Renewable and Sustainable Energy Reviews, 33, 554-565.

Mao, C., Shen, Q., Pan, W., \& Ye, K. (2015). Major barriers to off-site construction: The developer's perspective in China. Journal of Management in Engineering, 31(3), 04014043.

Mao, C., Xie, F., Hou, L., Wu, P., Wang, J., \& Wang, X. (2016). Cost analysis for sustainable off-site construction based on a multiple-case study in China. Habitat International, 57, 215-222.

Miller, R., Hobday, M., Lerouxdemers, T., \& Olleros, X. (1995). Innovation in Complex Systems Industries: the Case of Flight Simulation. Industrial \& Corporate Change, 4(2), 363-400.

Nadim, W., \& Goulding, J. S. (2010). Offsite production in the UK: the way forward? A UK construction industry perspective. Construction innovation, 10(2), 181-202.

Nadim, W., \& Goulding, J. S. (2011). Offsite production: a model for building down barriers: A European construction industry perspective. Engineering, Construction and Architectural Management, 18(1), 82-101.

Pan, W., \& Goodier, C. (2011). House-building business models and off-site construction take-up. Journal of Architectural Engineering, 18(2), 84-93.

Pan, W., Gibb, A. G. F., \& Dainty, A. R. J. (2012). Strategies for Integrating the Use of Off-Site Production Technologies in House Building. Journal of Construction Engineering \& Management, 138(11), 1331-1340.

Pan, W., Gibb, A. G., \& Dainty, A. R. (2007). Perspectives of UK housebuilders on the use of offsite modern methods of construction. Construction management and Economics, 25(2), 183-194.

Pan, W., Gibb, A. G., \& Dainty, A. R. (2008). Leading UK housebuilders' utilization of offsite construction methods. Building Research \& Information, 36(1), 56-67.

Polat, G. (2008). Factors Affecting the Use of Precast Concrete Systems in the United States. Journal of Construction Engineering \& Management, 134(3), 169-178.

Polat, G. (2010). Precast concrete systems in developing vs. industrialized countries. Journal of Civil Engineering \& Management, 16(1), 85-94.

Rajaprasad, S. V. S., \& Chalapathi, P. V. (2015). Factors influencing implementation of OHSAS 18001 in Indian construction organizations: interpretive structural modeling approach. Safety and health at work, 6(3), 200-205.

SC. (2014). National New-type Urbanization Plan (2014-2020). Beijing.

Shen, L., Song, X., Wu, Y., Liao, S., \& Zhang, X. (2016). Interpretive Structural Modeling based factor analysis on the implementation of Emission Trading System in the Chinese building sector. Journal of Cleaner Production, 127, 214-227.

Slaughter, E. S. (2000). Implementation of construction innovations. Building Research \& Information, 28(1), 2-17. 
Steinhardt, D. A., \& Manley, K. (2016). Adoption of prefabricated housing-the role of country context. Sustainable Cities and Society, 22, 126-135.

Steinhardt, D. A., Manley, K., \& Miller, W. (2013). Reshaping housing : the role of prefabricated systems. Building Construction Management \& Project Planning.

Tam, V. W. Y., Tam, C. M., Zeng, S. X., \& Ng, W. C. Y. (2007). Towards adoption of prefabrication in construction. Building \& Environment, 42(10), 3642-3654.

Teng, Y., Mao, C., Liu, G., \& Wang, X. (2017). Analysis of stakeholder relationships in the industry chain of industrialized building in China. Journal of Cleaner Production, 152, 387-398.

Wang, G. H., Wang, Y. X., \& Zhao, T. (2008). Analysis of interactions among the barriers to energy saving in China. Energy Policy, 36(6), 1879-1889.

Wang, T., Li, Y., Zhang, L., \& Li, G. (2016). Case Study of Integrated Prefab Accommodations System for Migrant On-Site Construction Workers in China. Journal of Professional Issues in Engineering Education and Practice, 142(4), 05016005.

Wu, W. S., Yang, C. F., Chang, J. C., Château, P. A., \& Chang, Y. C. (2015). Risk assessment by integrating interpretive structural modeling and Bayesian network, case of offshore pipeline project. Reliability Engineering \& System Safety, 142, 515-524.

Xue, X., Zhang, R., Yang, R., \& Dai, J. (2014). Innovation in Construction: A Critical Review and Future Research. International Journal of Innovation Science, 6(2), 111-126.

Xue, X., Zhang, X., Wang, L., Skitmore, M., \& Wang, Q. (2017). Analyzing collaborative relationships among industrialized construction technology innovation organizations: a combined SNA and SEM approach. Journal of Cleaner Production.

Zhai, X., Reed, R., \& Mills, A. (2014). Factors impeding the offsite production of housing construction in China: an investigation of current practice. Construction Management and Economics, 32(1-2), 40-52.

Zhang, X., \& Skitmore, M. (2012). Industrialized housing in China: a coin with two sides. International Journal of Strategic Property Management, 16(2), 143-157.

Zhang, X., Skitmore, M., \& Peng, Y. (2014). Exploring the challenges to industrialized residential building in China. Habitat International, 41(41), 176-184. 